\title{
Anti-Inflammatory Dimethylfumarate: A Potential New Therapy for Asthma?
}

\author{
Petra Seidel $^{1}$ and Michael Roth ${ }^{1,2}$ \\ ${ }^{1}$ Pulmonary Cell Research, Department of Biomedicine, University of Basel, Hebelstraße 20, 4031 Basel, Switzerland \\ ${ }^{2}$ Pneumology, Department of Internal Medicine, University Hospital Basel, Petersgraben 4, 4031 Basel, Switzerland \\ Correspondence should be addressed to Michael Roth; michael.roth@usb.ch
}

Received 11 December 2012; Revised 7 February 2013; Accepted 7 February 2013

Academic Editor: Gustavo Duarte Pimentel

Copyright ( 2013 P. Seidel and M. Roth. This is an open access article distributed under the Creative Commons Attribution License, which permits unrestricted use, distribution, and reproduction in any medium, provided the original work is properly cited.

\begin{abstract}
Asthma is a chronic inflammatory disease of the airways, which results from the deregulated interaction of inflammatory cells and tissue forming cells. Beside the derangement of the epithelial cell layer, the most prominent tissue pathology of the asthmatic lung is the hypertrophy and hyperplasia of the airway smooth muscle cell (ASMC) bundles, which actively contributes to airway inflammation and remodeling. ASMCs of asthma patients secrete proinflammatory chemokines CXCL10, CCL11, and RANTES which attract immune cells into the airways and may thereby initiate inflammation. None of the available asthma drugs cures the disease-only symptoms are controlled. Dimethylfumarate (DMF) is used as an anti-inflammatory drug in psoriasis and showed promising results in phase III clinical studies in multiple sclerosis patients. In regard to asthma therapy, DMF has been anecdotally reported to reduce asthma symptoms in patients with psoriasis and asthma. Here we discuss the potential use of DMF as a novel therapy in asthma on the basis of in vitro studies of its inhibitory effect on ASMC proliferation and cytokine secretion in ASMCs.
\end{abstract}

\section{Introduction}

Asthma is a disease of the airways characterized by chronic inflammation associated with airway hyperresponsiveness (AHR) and airway wall remodeling. In the past decades, numerous immunological studies of lung fluids and animal studies suggested that asthma is a disease caused by the deregulation of the immune response to inhaled or eaten allergens that leads to structural changes of the airway tissue which increase with the duration of the disease [1-3]. New clinical studies, especially in childhood asthma, suggest that inflammation and remodeling occur independent of each other in parallel or even that airway wall remodeling especially of the airway smooth muscle occurs before any signs of inflammation can be found [4-7]. Therefore the question if the pathophysiology of the airway smooth muscle cell is crucial for the pathogenesis of asthma was reactivated [8].

The increased mass of cells within airway smooth muscle (ASM) bundles is one of the most striking pathological features in the asthmatic airway and inversely correlates with lung function in asthma [9]. The role of the airway epithelium as a master regulator of airway wall forming cells has recently been demonstrated; however, the mechanism(s) by which a deranged epithelium affects the underlying cell types has to be studied in more detail [10]. In Figure 1, we provide two examples of the airway wall obtained from nonasthmatic adults and from two moderate asthmatics. Both tissue sections of the asthmatic airways demonstrate the well-known loss of epithelium integrity, the significant increase of the basement membrane thickness, and the increased number of ASM bundles. In contrast, there is no clear increase of the thickness and structure of the subepithelial fibroblast/myofibroblast cell layer (Figure 1).

Recent studies support the hypothesis that the increase of the ASM bundles in the airway wall of asthma patients is an early event developing independently in parallel to inflammation [4-7]. Comparing the airway wall structure in biopsy material of 53 school children with treatmentresistant asthma to that of 16 healthy age-matched controls provided evidence that remodeling, especially the increase of ASM bundle size, was independent of proinflammatory 


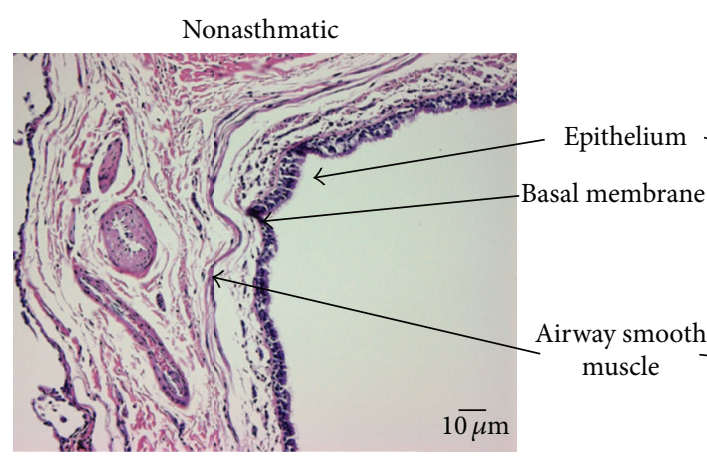

(a)

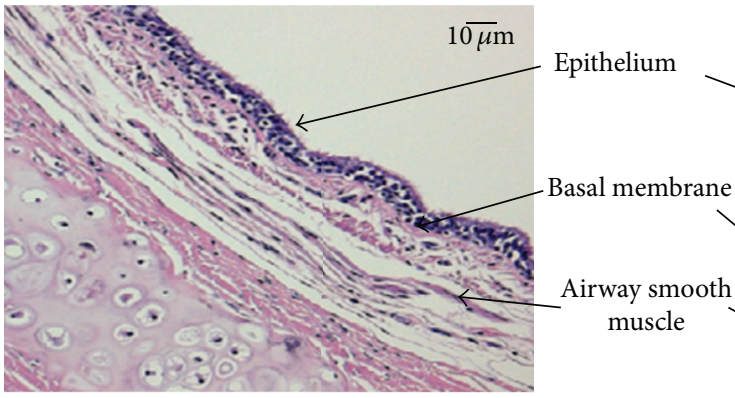

(b)

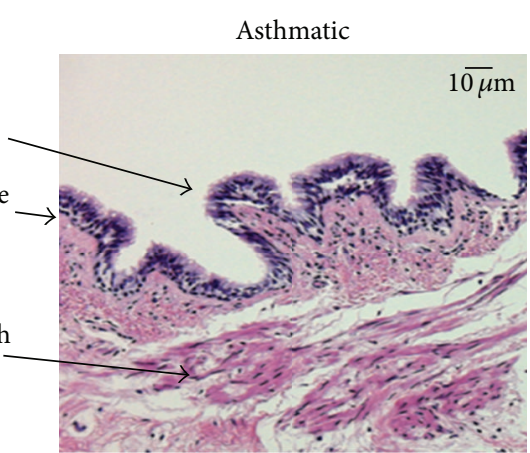

(c)

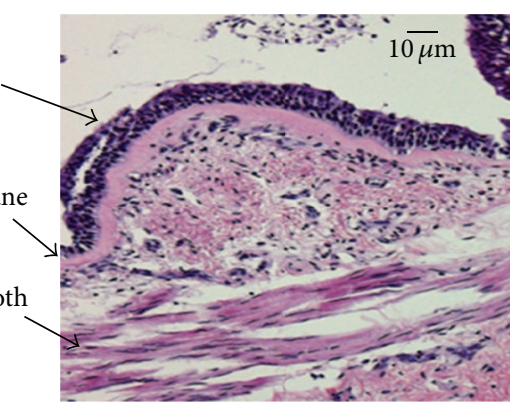

(d)

FIgURE 1: Histological tissue sections of two patients with moderate asthma and two nonasthma controls. Arrows indicate the loss of epithelium integrity, the increase of the basement membrane thickness, and the increased number of ASM bundles in the asthmatic airways (c, d), compared to nonasthmatic airways $(a, b)$.

Th2-cell derived cytokines (IL-4, IL-5, and IL-13), while eosinophil counts varied over a wide range [4]. Assessing endobronchial biopsy specimen of ASM obtained from 47 wheezing preschool children and 21 nonwheezing controls, it was documented that an increased mass of ASM occurred in the majority of wheezing children [7]. In a nonhuman primate model of asthma and COPD, a striking rearrangement of the smooth muscle cell bundles from a nonstructured into a spiral-like formation surrounding the airway was described $[11,12]$. These findings suggested that allergic as well as nonallergic asthma triggers induce a pathological reorganization of ASM bundles by an unknown mechanism. Furthermore, it was reported that inhalation of either methacholine or house dust mite allergens by volunteering patients with mild asthma leads to airway wall remodeling within only eight days, which was prevented by inhalation of a long-acting $\beta 2$-agonist [5]. In addition, removal of ASM cells by thermoplasty significantly reduced asthma symptom of several years and is today regarded as a therapeutic option for severe asthma [13-15]. Several in vitro and in vivo studies have shown that ASM cells (ASMCs) secrete a variety of mediators, which enable them to interact with immune cells and to modulate the inflammatory response and remodeling in asthma $[9,16,17]$. Together these observations strongly support the central role of ASMC in the pathogenesis of asthma and therefore they are interesting targets for asthma therapy $[18,19]$.

Inhaled long-acting $\beta 2$-agonists (LABAs) combined with glucocorticoids (GCs) remain the most effective therapy for asthma. However, a considerable number of asthma patients do not respond to inhaled GCs [20]. In addition, the current therapy only controls disease symptoms, but none of the existing asthma medications cures the disease. This emphasizes a need for new therapeutic options to treat asthma more efficiently [21-23].

Dimethylfumarate (DMF) is a potent anti-inflammatory medication for psoriasis and it has also been shown to suppress inflammation in other chronic inflammatory diseases, especially MS [24]. Interestingly, DMF has been anecdotally reported to reduce asthma symptoms in patients suffering from asthma and psoriasis. In experimental studies, DMF inhibited proliferation and proinflammatory transcription factors as well as the secretion of asthma-relevant cytokines in primary human lung cells [25-28]. In this paper we describe how ASMC-derived CXCL10, CCL11, or RANTES may contribute to airway inflammation in asthma and how these chemokines can be controlled by the anti-inflammatory action of DMF.

\section{Airway-Smooth-Muscle-Cell-Derived Chemokines Contribute to Airway Inflammation}

ASMC hyperplasia and hypertrophy in asthmatic airways had already been described in 1922 and was considered as the main cause of AHR [8]. Interestingly, in recent years it became evident that ASMCs hypertrophy may precede inflammation and that ASMC are an important source of inflammatory mediators and therefore actively contribute 
to airway inflammation [4-6]. Proinflammatory cytokines activate the ASMC to secrete further chemokines that subsequently attract immune cells such as mast cells [16] or T lymphocytes [9] into the ASM bundle. These immune cells then interact with ASMC and alter their contractile function, enhance proliferation, and further amplify the secretion of proinflammatory factors. For instance, it has been reported that mast-cell-derived tryptase enhanced ASMC contractility [29], induced ASMC proliferation [30], and increased TGF$\beta 1$ secretion [31]. Similarly, T lymphocytes infiltrated the asthmatic ASM bundle and induced ASMC proliferation $[9,32]$. In the following, we will focus on ASMC-derived chemokines CXCL10, CCL11 (eotaxin), and RANTES, which are crucially involved in the trafficking of immune cells into the airway in asthma.

\section{CXCL10 (IP-10)}

ASMC-derived CXCL10 is a potent chemoattractant for human lung mast cells [33]. In a disease-specific pattern, ASM bundles are infiltrated by activated mast cells in asthma, as this pathology was neither observed in patients with eosinophilic bronchitis nor in nonasthmatic controls [16, 34]. Consequently, it was hypothesized that the ASMC itself attracts mast cells by secreting chemokines such as CXCL10. This assumption was supported by studies in ASMC of asthma patients, which expressed higher levels of CXCL10 than ASMC derived from nonasthmatic controls. In addition, CXCL10 has been detected in the ASM bundles of asthmatic airway biopsies only and all mast cells within the ASM bundles expressed CXCR3, which is the receptor for CXCL10 [33]. A wide range of asthma relevant stimuli have been reported to increase signaling pathways that may lead to incerased CXCL10 secretion [35-38].

CXCL10 is secreted by ASMC after stimulation with proinflammatory cytokines such as TNF- $\alpha$, IFN- $\gamma$, or IL$1 \beta$, which activated MAPK JNK, NF- $\kappa$ B, STAT 1 , and the transcriptional coactivator CREB-binding protein $[25,39-$ 41]. In addition, CXCL10 secretion by ASMC is sensitive to changes in cellular glutathione (GSH) levels [27], suggesting a link of this signaling pathway to the asthma-associated upregulation of mitochondria, which control the cellular redox system [42]. Interestingly, the thiazolidinedione ciglitazone strongly inhibited cytokine-induced CXCL10 protein without affecting CXCL10 mRNA level, suggesting that CXCL10 is regulated on the posttranslational level in ASMC [41]. In this context, it would be of interest if the posttranscriptional regulation of CXCL10 in asthma occurs through the recently described modified translation control [43].

\section{CCL11 (Eotaxin)}

CCL11 is a potent eosinophil chemoattractant and eosinophilia is a prominent pathology of the asthmatic airway [44-46]. In vivo, the asthmatic ASM bundle showed strong signals of CCL11 immunoreactivity and CCL11 mRNA [47]. In addition, in bronchial biopsies of asthmatic patients, CCL11 expression correlated with asthma severity $[44,48]$.
In vitro, ASMC secreted CCL11 $[26,35]$ and it has been shown that ASMCs derived from asthmatic patients produce higher levels of CCL11 mRNA and protein than those derived from nonasthmatic controls $[49,50]$. CCL11 secretion from ASMCs can be induced by Th1 and Th2 cytokines including TNF- $\alpha$, IL- $1 \beta$, IL-13, or IL- $4[26,35,51,52]$ and critically involves the activation of NF- $\kappa \mathrm{B}[26,35]$. In addition to its chemoattractant function, CCL11 has been proposed to stimulate ASMC hyperplasia, as ASMCs express the CCL11 receptor CCR3, which, upon activation, induces ASMC migration but in this study did not induce ASMC proliferation [49]. However, in a different study CCL11 increased $\left[{ }^{3} \mathrm{H}\right]$-thymidine incorporation and DNA synthesis and decreased the rate of apoptosis in ASMC [53].

\section{RANTES}

RANTES is a chemoattractant for eosinophils, T cells, and monocytes and thus has been linked to asthma pathology $[54,55]$. In asthma, the ASM bundles are infiltrated by T lymphocytes [9] and ASMCs produce elevated levels of RANTES mRNA [56]. ASMC-derived RANTES was therefore proposed to participate in the chemotaxis of T lymphocytes to the ASM bundle. IFN- $\gamma$ and TNF- $\alpha$ stimulated RANTES secretion from ASMC in vitro $[26,35,51]$ and this was dependent on the activation of NF- $\kappa \mathrm{B}[26,35]$, MAPK JNK [57], and AP-1 [58]. Like CCL11, RANTES participated in airway remodeling by inducing ASMC proliferation and migration [53, 59]. Interestingly, recombinant RANTES is degraded by mast cell tryptase and thereby reduced RANTES-activated chemotaxis of eosinophils [55]. Furthermore, mast-cell-derived histamin has been shown to reduce RANTES secretion by ASMC in vitro [60]. The inactivation of RANTES by mast-cell-derived mediators might explain the phenomenon that the asthmatic ASM bundle is infiltrated by a much higher number of mast cells than of $\mathrm{T}$ lymphocytes [16].

\section{Dimethylfumarate (DMF)}

DMF is the ester of the unsaturated dicarboxylic fumaric acid (Figure 2). The German chemist Walter Schweckendieck described the anti-inflammatory properties of DMF in 1959 [61]. Schweckendieck postulated that psoriasis is caused by a dysfunctional citric acid cycle and hypothesized that DMF is metabolized to fumaric acid, which enters the citric acid cycle and thereby inhibits the inflammatory processes. Schweckendieck tested several forms of fumarates in selfexperiments and his psoriasis improved [61]. Based on his findings, the physician Günther Schäfer developed a psoriasis therapy with a mixture of fumaric acid esters. In 1989 a controlled clinical study proved the efficacy of DMF in psoriasis [62] and soon thereafter a mixture of DMF with calcium, magnesium, and zinc salts of ethyl hydrogen fumarate was registered in Germany as Fumaderm for the systemic treatment of psoriasis. Fumaderm is widely used for the treatment of moderate to severe psoriasis vulgaris in Northern Europe [24, 63-65]. In 2003 a second-generation 


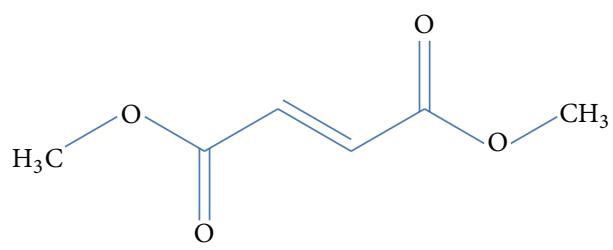

FIgURE 2: Chemical structure of dimethylfumarate.

fumaric acid derivate, BG-12, which only contains DMF in enteric-coated microtablets, has been developed (no authors listed BG 12). BG-12 has been successfully tested in phase II and III clinical studies for the oral treatment of multiples sclerosis [66-68].

\section{Clinical Use and Pharmacokinetic of DMF}

Fumaderm is administered orally in slowly increasing doses till a clinical effect is observed. The initial dose is $30 \mathrm{mg}$ DMF per day, which can be increased to a maximum daily dose of $720 \mathrm{mg}$ DMF $[64,65,69]$. In several clinical studies, Fumaderm showed an excellent antipsoriatic effect causing an improvement of about $75 \%$ of the baseline PASI (psoriasis area and severity index) in up to $70 \%$ of the patients tested [64, 69-71]. Even though side effects such as gastrointestinal complaints or flushing occur, Fumaderm has been shown to be very safe as long-term treatment for psoriasis with no longterm toxicity, higher risk for infections or malignancies [72].

Although Fumaderm has been used for many years, its pharmacokinetic is still poorly understood. DMF is the main ingredient of Fumaderm and is clinically most efficacious [73]. However, after oral administration of Fumaderm only, monomethylfumarate (MMF) with serum peak concentrations at around $20 \mu \mathrm{M}$, but not DMF, was detectable in blood plasma $[68,74]$. It was therefore hypothesized that DMF's hydrolysis-product MMF is the actual active compound. However, this notion has been questioned by many in vitro studies showing that MMF is pharmacologically less effective when compared to DMF. For instance, in human endothelial cells, DMF reduced the expression of VCAM-1, ICAM-1, and E-selectin with $\mathrm{IC}_{50}$ values of approximately $50 \mu \mathrm{M}$, whereas monoethylfumarate at concentrations of $10-100 \mu \mathrm{M}$ showed no inhibitory effect [75]. Similarly, in human keratinocytes, DMF at concentrations of $7-140 \mu \mathrm{M}$ inhibited IL- $1 \beta$-induced phosphorylation of MSK-1, whereas MMF at $140 \mu \mathrm{M}$ had no effect on MSK-1 activation [76]. DMF has been shown to rapidly react with glutathione $(\mathrm{GSH})$ under physiological conditions in vitro [77]. It was therefore proposed that DMF is released into the bloodstream where it is absorbed by cells and conjugated to GSH, explaining why DMF is not detectable in plasma after oral intake. This assumption was supported by a study, showing that DMF-GSH-conjugate metabolites are secreted in the urine of DMF-treated psoriasis patients [78]. However, the complex pharmacokinetic of DMF makes it difficult to relate concentrations of DMF used in cell culture models to DMF concentrations in target tissue or plasma levels in vivo.

\section{The Anti-Inflammatory Action of DMF in Psoriasis}

Several in vitro and in vivo studies have proven the potent anti-inflammatory effects of DMF and its favorable safety profile in the treatment of psoriasis [79]. DMF reduced the proinflammatory contribution of several cell types including $\mathrm{T}$ lymphocytes, mononuclear blood cells, dendritic cells (DCs), endothelial cells, and keratinocytes, which are all crucially involved in the inflammatory process in psoriasis, as will be discussed in the following.

In purified human $\mathrm{T}$ lymphocytes, DMF inhibited the proinflammatory transcription factor $\mathrm{NF}-\kappa \mathrm{B}$ and induced apoptosis $[80,81]$. In vivo studies in psoriasis patients showed that DMF reduced the total number of peripheral blood $\mathrm{T}$ lymphocytes and the number of $\mathrm{T}$ lymphocytes in psoriatic lesions $[82,83]$. Regarding its anti-inflammatory action, DMF inhibited the maturation of DC by reducing the expression of interleukin- (IL-) 12, IL-6, major histocompatibility complex (MHC) class II, cluster of differentiation (CD)80, and CD86, mainly through the inhibition of NF- $\kappa \mathrm{B}$, and mitogen- and stress-activated protein kinase- (MSK-) 1 . These immature DCs were shown to generate fewer IFN- $\gamma$ - and IL17-producing T lymphocytes [84].

In human keratinocytes and mononuclear blood cells, DMF inhibited mRNA and protein expression of CXCL8, CXCL9, and CXCL10 [85]. Furthermore, the expression of CXCL8 and IL-20 mRNA in human keratinocytes was inhibited by DMF, which was mediated by reduced MSK$1, \mathrm{NF}-\kappa \mathrm{B}$, and $\mathrm{cAMP}$ response element-binding protein (CREB) activation [76, 86]. In human peripheral blood mononuclear cells, DMF reduced GSH level and upregulated heme oxygenase- (HO-) 1 expression, which resulted in the inhibition of TNF- $\alpha$, IL-12, and IFN- $\gamma$ secretion [87]. In addition, DMF inhibited macrophage migration inhibitory factor- (MIF-) induced human keratinocytes proliferation by reducing MSK-1, $90 \mathrm{kDa}$ ribosomal S6 kinase (RSK), CREB, and JunB phosphorylation [86].

In endothelial cells, DMF inhibited the nuclear entry of $\mathrm{NF}-\kappa \mathrm{B}$, resulting in a reduced expression of TNF-induced tissue factor [88]. Furthermore, the expression of the adhesion molecules intercellular adhesion molecule- (ICAM-) 1, vascular cell adhesion molecule- (VCAM-) 1, and E-selectin on endothelial cells was inhibited by DMF, resulting in impaired lymphocyte rolling and adhesion [89]. DMF also had antiangiogenic properties by the inhibition of vascular endothelial growth factor receptor (VEGFR)2 expression on human endothelial cells [90].

\section{DMF as Potential Treatment for Multiple Sclerosis}

Multiple sclerosis (MS) is a chronic disease of the central nervous system, which is characterized by inflammation, demyelination, axonal loss, and glial proliferation. Currently therapy for MS is parenteral administered and is only partially effective, as patients do not remain relapse-free after treatment [91]. Clinical phase II and III studies investigating 
a potential use of DMF for oral treatment of relapsingremitting MS (RRMS) as well as a number of in vitro studies on MS-relevant cells have shown very promising results.

\section{Clinical Studies}

Schimrigk et al. [92] performed the first open-label, baseline controlled clinical study with Fumaderm in patients with RRMS. They showed that Fumaderm treatment significantly decreased the number and volume of gadolinium-enhancing lesions. In addition, they reported elevated levels of the cytokine IL-10 and decreased expression of the proinflammatory cytokine IFN- $\gamma$. Furthermore, they found that apoptosis was increased in lymphocytes [92]. In 2008, Kappos et al. [66] published the results of a multicentre, randomized, double-blind, placebo-controlled phase IIb study testing the efficacy and safety of BG-12 (contains DMF only) in RRMS patients. Patients treated with BG-12 showed a dosedependent reduction of MS lesions compared to the placebo group and there was a trend of a lower annualized relapse rate. BG-12 was generally well tolerated and showed a favorable safety profile [66]. This study was followed by a placebocontrolled phase III clinical study, confirming that BG-12 treatment resulted in a significant reduction of MS lesions compared to placebo. Furthermore, the study showed that the proportion of patients who had a relapse as well as the annualized relapse rate was reduced and a decrease of the disability progression rate was observed in BG-12-treated MS patients $[67,93]$.

\section{Mode of Action of DMF in MS}

DMF has been shown to initially reduce cellular reduced glutathione (GSH) in different cell types, including neuronal cells [94] and astrocytes [95], which resulted in the activation of the Nrf2 (nuclear factor erythroid-derived-2- (E2) related factor)/Keap-1 pathway in astrocytes, neuronal cells, and primary central nervous system cells [94-96]. A reduction of GSH and an activation of Nrf2 induced the expression of antioxidant enzymes such as $\mathrm{NAD}(\mathrm{P}) \mathrm{H}$ quinone oxidoreductase- (NQO-) 1, glutamate-cysteine ligase catalytic subunit (GCLC), or HO-1, resulting in reduced oxidative stress, proinflammatory cytokine secretion, and proliferation in these cells $[87,94,95]$. Therefore, the activation of the antioxidant Nrf-2 pathway is regarded to mediate DMF's beneficial effects in MS.

\section{DMF as a Potential Asthma Therapy}

In primary human lung mesenchymal cells, DMF inhibited the activation of the proinflammatory transcription factor $\mathrm{NF}-\kappa \mathrm{B}[26,28,35]$. NF- $\kappa \mathrm{B}$ activity was reported to be increased in the airways of asthmatic patients [97]. In addition, proinflammatory cytokines such as TNF- $\alpha$ activated $\mathrm{NF}-\kappa \mathrm{B}$ in ASMC in vitro, which resulted in the secretion of a variety of proinflammatory factors including RANTES, CXCL10, or CCL11 $[26,27,35]$. In vitro, inhibition of NF$\kappa \mathrm{B}$ downregulated the release of a range of proinflammatory mediators by ASMC [98]. Furthermore, the inhibition of NF$\kappa \mathrm{B}$ reduced airway inflammation in a mouse model of asthma [99].

In resting cells, $\mathrm{NF}-\kappa \mathrm{B}$ is retained in the cytosol in a complex formed with $\mathrm{I} \kappa \mathrm{B}$ (inhibitor of $\mathrm{NF}-\kappa \mathrm{B}$ ). Upon stimulation, $\mathrm{I} \kappa \mathrm{B}$ is degraded, which allows free and activated NF- $\kappa \mathrm{B}$ to enter the nucleus where it binds to specific NF- $\kappa \mathrm{B}$-sensitive DNA sequences which are located within the promoter regions of many proinflammatory genes [100]. NF- $\kappa \mathrm{B}$ activity is regulated by posttranslational modifications such as phosphorylation, glutathionylation, or modification of histones that wind up NF- $\kappa \mathrm{B}$ target genes. Protein glutathionylation is a redox-regulated process, whereby a cysteine-thiol of a protein forms a disulfide bond with the cysteine-thiol of GSH [101]. Interestingly, $\mathrm{I} \kappa \mathrm{B} \alpha$ contains cysteine thiols, which are susceptible to glutathionylation [102].

In human cultured ASMC, DMF inhibited the nuclear entry of NF- $\kappa$ B and the binding of NF- $\kappa$ B to the corresponding DNA sequence $[26,35]$. In a subsequent study, we provided evidence that the inhibitory effect of DMF on NF- $\kappa \mathrm{B}$ nuclear entry is mediated by glutathionylation of $\mathrm{I} \kappa \mathrm{B} \alpha$, which inhibited its degradation [35]. Furthermore, DMF reduced NF- $\kappa$ B phosphorylation and altered the chromatin environment by inhibiting MSK-1-induced histone H3 phosphorylation in ASMC and keratinocytes [26, 35, 86]. Consequently, DMF inhibited the secretion of NF- $\kappa$ B-dependent cytokines such as interleukin (IL)-6, GM-CSF, eotaxin, RANTES, and CXCL10 when stimulated with TNF- $\alpha$ in ASMC and lung fibroblasts $[25,26,28,38]$. An interesting study by Van Ly et al. has shown that DMF increased rhinovirus (RV) replication and failed to reduce RV-induced IL- 6 and IL- 8 by human lung fibroblasts [37]. In another study on HIV-infected monocytederived macrophages, DMF reduced HIV replication and neurotoxin release [103]. This suggests a virus-specific effect of DMF leaving it an open question whether DMF may help to control virus-induced asthma exacerbations.

In addition to NF- $\kappa \mathrm{B}$ inhibition, DMF downregulated the secretion of PDGF-BB-induced IL- 6 by airway smooth muscle cells and lung fibroblasts, which was most likely mediated by DMF's inhibitory effect on AP-1 and CREB in these cells $[26,28]$. Besides inhibition of proinflammatory cytokine secretion, DMF was shown to reduce PDGF-BBstimulated ASMC and lung fibroblast proliferation, suggesting a beneficial effect on airway remodeling in asthma [28, 36].

The airways of asthma patients are exposed to increased oxidative stress [104], which may alter ASMC proliferation and proinflammatory cytokine secretion through redoxsensitive signaling pathways $[105,106]$. As described earlier, DMF activated the Nrf2 antioxidant response pathway, by reducing cellular GSH levels [94-96]. Once activated, Nrf2 binds to the antioxidant response elements (AREs) within the promoter of antioxidant genes such as HO-1 initiating their transcription. DMF reduced intracellular-reduced GSH level and upregulated HO-1 in ASMC [27, 35]. HO-1 is an inducible enzyme, which protects the lungs from increased oxidative stress [107]. In addition, HO-1 protected the lungs against hyperoxic injury and attenuated allergen-induced airway inflammation and hyperreactivity in animal models 
TABLE 1: DMF effects on primary human lung cells.

\begin{tabular}{|c|c|c|c|c|}
\hline Factors & DMF effect & After stimulation & Cell type & Reference \\
\hline CXCL10 & Inhibition at $10-100 \mu \mathrm{M}$ DMF & TNF- $\alpha$ and/or IFN- $\gamma$ and/or IL-1 $\beta$ & ASMC & {$[25,27]$} \\
\hline G-CSF & $\begin{array}{c}\text { No effect } \\
\text { Inhibition at } 10 \mu \mathrm{M} \text { DMF }\end{array}$ & $\begin{array}{l}\text { IFN- } \gamma \\
\text { TNF- } \alpha\end{array}$ & ASMC & {$[27]$} \\
\hline Eotaxin & Inhibition at $10-100 \mu \mathrm{M}$ DMF & TNF- $\alpha$ & ASMC & {$[26,35]$} \\
\hline RANTES & Inhibition at $10-100 \mu \mathrm{M}$ DMF & TNF- $\alpha$ & ASMC & {$[26,35]$} \\
\hline IL-8 & No effect at $0.01-1 \mu \mathrm{M}$ DMF & Rhinovirus & Lung fibroblasts & {$[37]$} \\
\hline GM-CSF & Inhibition at $100 \mu \mathrm{M}$ DMF & $\begin{array}{l}\text { TNF- } \alpha \text { and IL-1 } \beta \text { prior to stimulation } \\
\text { with human serum }(10 \%)\end{array}$ & ASMC & {$[38]$} \\
\hline \multirow{2}{*}{ IL-6 } & Inhibition at $10-100 \mu \mathrm{M}$ DMF & TNF- $\alpha$ or PDGF-BB & ASMC and lung fibroblasts & {$[26,28]$} \\
\hline & No effect at $0.01-1 \mu \mathrm{M}$ DMF & Rhinovirus & Lung fibroblasts & {$[37]$} \\
\hline Cell proliferation & Inhibition at $10-100 \mu \mathrm{M}$ DMF & PDGF-BB & ASMC and lung fibroblasts & {$[28,36]$} \\
\hline
\end{tabular}

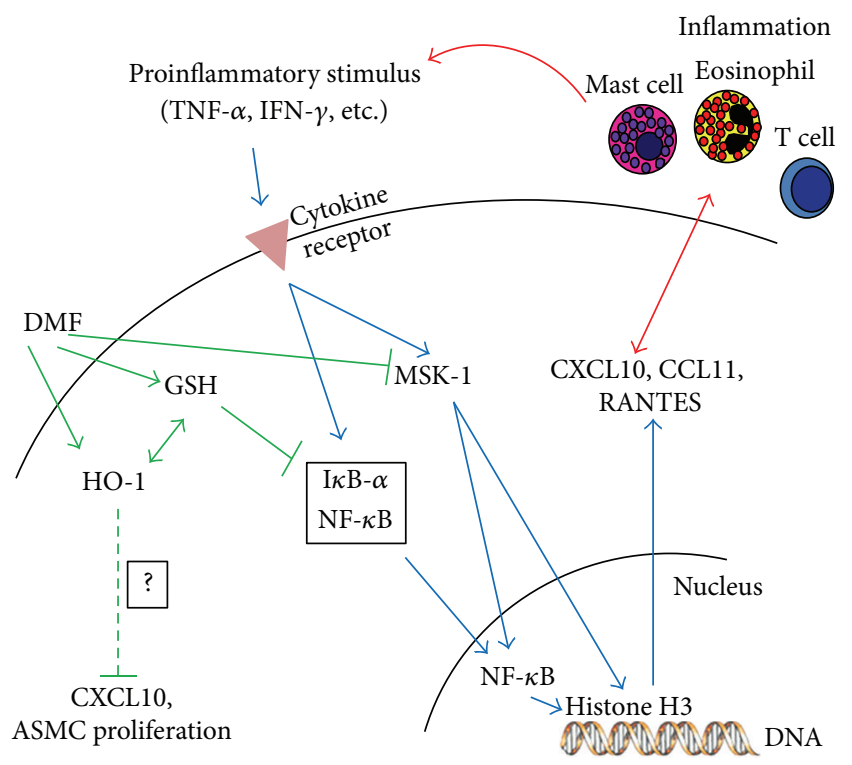

FIgURE 3: Secretion of chemokines such as CXCL10, CCL11, or RANTES by ASMC attracts immune cells (eosinophils, T cells, or mast cells) into the asthmatic airway. In turn, these immune cells secrete proinflammatory cytokines (TNF- $\alpha$, IFN- $\gamma$, etc.), which stimulate proinflammatory signaling molecules such as NF- $\kappa \mathrm{B}$ or MSK-1 in ASMC, enhancing its proinflammatory function. DMF reduces intracellular reduced glutathione (GSH) level and thereby induces $\mathrm{HO}-1$ expression and $\mathrm{I} \kappa \mathrm{B}$-glutathionylation. DMF-induced HO-1 decreased CXCL10 and ASMC proliferation by an unknown mechanism. I $\kappa \mathrm{B}$-glutathionylation inhibited $\mathrm{I} \kappa \mathrm{B}$ degradation and subsequent NF- $\kappa \mathrm{B}$ nuclear entry. Furthermore, DMF inhibited MSK-1-mediated histone $\mathrm{H} 3$ and $\mathrm{NF}-\kappa \mathrm{B}$ phosphorylation, leading to reduced secretion of CXCL10, CCL11, and RANTES. DMF reduces ASMC chemokine secretion and may therefore inhibit the crosstalk between ASMC and immune cells, leading to airway inflammation.

of asthma [108, 109]. We demonstrated that DMF induced HO- 1 and thereby inhibited PDGF-BB-induced ASMC proliferation and CXCL10 secretion $[27,36]$. Importantly, DMF inhibited CXCL10 by ASMCs more efficiently when combined with the GC fluticasone, suggesting a GC sparing effect of DMF [27]. Furthermore, others have shown that activation of Nrf 2 and induction of HO- 1 inhibit TGF- $\beta$-induced ASMC proliferation and secretion of IL-6 [110]. In this context, it is of importance that in ASMC-derived from patients with severe asthma the binding of $\mathrm{Nrf} 2$ to the antioxidant response elements as well as the expression of HO-1 was reduced when compared to ASMC of nonasthmatic controls [110] suggesting that activation of $\mathrm{Nrf} 2$ and upregulation of HO-1 by DMF may compensate this pathology. Together these results emphasize a potential beneficial effect of Nrf2mediated HO-1 induction in asthma. Regarding other antiinflammatory actions of DMF, it reduced CXCL10 expression in cells stimulated with either a cytomix (IL- $1 \beta$, TNF- $\alpha$, and IFN- $\gamma$ in combination) or IFN- $\gamma$ alone, which has been shown to be insensitive to GC therapy [25, 27, 41]. Thus DMF may act as an anti-inflammatory drug in steroid-resistant asthma and significantly reduce healthcare costs. A summary of DMF effects on primary lung cells is summarized in Table 1 and the postulated beneficial action of DMF is provided in Figure 3.

\section{Conclusion}

Current asthma therapy is not sufficient to control symptoms in all asthma patients and does not cure the disease. Thus, it is important to find new therapeutic options to treat asthma. CXCL10, CCL11, and RANTES derived from ASMC are believed to be crucially involved in chemotaxis of immune cells into the asthmatic airways and are therefore actively involved in the development of airway inflammation in asthma. DMF reduced the secretion of CXCL10, CCL11, and RANTES as well as ASMC proliferation by inhibiting the proinflammatory transcription factor $\mathrm{NF}-\kappa \mathrm{B}$ and by upregulation of HO-1. Furthermore, DMF overcame GC resistance and had a GC-sparing effect in a cell culture model of asthma. Taken together, DMF's strong anti-inflammatory and antiproliferative effects in cultured human ASMC suggest that it may be beneficial in asthma therapy. 


\section{References}

[1] S. T. Holgate, "Innate and adaptive immune responses in asthma," Nature Medicine, vol. 18, no. 5, pp. 673-683, 2012.

[2] K. Mullane, "The increasing challenge of discovering asthma drugs," Biochemical Pharmacology, vol. 82, no. 6, pp. 586-599, 2011.

[3] C. S. Stevenson and M. A. Birrell, "Moving towards a new generation of animal models for asthma and COPD with improved clinical relevance," Pharmacology and Therapeutics, vol. 130, no. 2, pp. 93-105, 2011.

[4] C. J. Bossley, L. Fleming, A. Gupta et al., "Pediatric severe asthma is characterized by eosinophilia and remodeling without $\mathrm{T}_{\mathrm{H}} 2$ cytokines," Journal of Allergy and Clinical Immunology, vol. 129, no. 4, pp. 974-982, 2012.

[5] C. L. Grainge, L. C. K. Lau, J. A. Ward et al., "Effect of bronchoconstriction on airway remodeling in asthma," The New England Journal of Medicine, vol. 364, no. 21, pp. 2006-2015, 2011.

[6] A. L. James, J. G. Elliot, R. L. Jones et al., "Airway smooth muscle hypertrophy and hyperplasia in asthma," American Journal of Respiratory and Critical Care Medicine, vol. 185, no. 10, pp. 10581064, 2012.

[7] R. O’Reilly, N. Ullmann, S. Irving et al., "Increased airway smooth muscle in preschool wheezers who have asthma at school age," Journal of Allergy and Clinical Immunology, 2012.

[8] H. L. Huber and K. K. Koessler, "The pathology of bronchial asthma," Archives of Internal Medicine, vol. 30, pp. 689-760, 1922.

[9] D. Ramos-Barbón, R. Fraga-Iriso, N. S. Brienza et al., "T cells localize with proliferating smooth muscle $\alpha$-actin + cell compartments in asthma," American Journal of Respiratory and Critical Care Medicine, vol. 182, no. 3, pp. 317-324, 2010.

[10] B. N. Lambrecht and H. Hammad, "The airway epithelium in asthma," Nature Medicine, vol. 18, no. 5, pp. 684-692, 2012.

[11] M. U. T. Tran, A. J. Weir, M. V. Fanucchi et al., "Smooth muscle hypertrophy in distal airways of sensitized infant rhesus monkeys exposed to house dust mite allergen," Clinical and Experimental Allergy, vol. 34, no. 10, pp. 1627-1633, 2004.

[12] C. G. Plopper, S. M. Smiley-Jewell, L. A. Miller et al., "Asthma/allergic airways disease: does postnatal exposure to environmental toxicants promote airway pathobiology?" Toxicologic Pathology, vol. 35, no. 1, pp. 97-110, 2007.

[13] M. M. Wahidi and M. Kraft, "Bronchial thermoplasty for severe asthma," American Journal of Respiratory and Critical Care Medicine, vol. 185, no. 7, pp. 709-714, 2012.

[14] L. J. Janssen, "Airway smooth muscle as a target in asthma and the beneficial effects of bronchial thermoplasty," Journal of Allergy, vol. 2012, Article ID 593784, 9 pages, 2012.

[15] D. C. Doeing, A. K. Mahajan, S. R. White, E. T. Naureckas, J. A. Krishnan, and D. K. Hogarth, "Safety and feasibility of bronchial thermoplasty in asthma patients with very severe fixed airflow obstruction: a case series," Journal of Asthma, vol. 50, no. 2, pp. 215-218, 2012.

[16] C. E. Brightling, P. Bradding, F. A. Symon, S. T. Holgate, A. J. Wardlaw, and I. D. Pavord, "Mast-cell infiltration of airway smooth muscle in asthma," The New England Journal of Medicine, vol. 346, no. 22, pp. 1699-1705, 2002.

[17] D. S. Carnieli, E. Yoshioka, L. F. F. Silva et al., "Inflammation and remodeling in infantile, juvenile, and adult allergic sensitized mice," Pediatric Pulmonology, vol. 46, no. 7, pp. 650-665, 2011.
[18] J. L. Black, R. A. Panettieri Jr., A. Banerjee, and P. Berger, "Airway smooth muscle in asthma: just a target for bronchodilation?" Clinics In Chest Medicine, vol. 33, no. 3, pp. 543-558, 2012.

[19] A. Stewart, "More muscle in asthma, but where did it come from?" American Journal of Respiratory and Critical Care Medicine, vol. 185, no. 10, pp. 1035-1037, 2012.

[20] I. M. Adcock, P. A. Ford, P. Bhavsar, T. Ahmad, and K. F. Chung, "Steroid resistance in asthma: mechanisms and treatment options," Current Allergy and Asthma Reports, vol. 8, no. 2, pp. 171-178, 2008.

[21] K. Bond, C. Spooner, L. Tjosvold, C. Lemière, and B. H. Rowe, "The nature and influence of pharmaceutical industry involvement in asthma trials," Canadian Respiratory Journal, vol. 19, no. 4, pp. 267-271, 2012.

[22] Y. Nakamura, "Developmental current and future therapy for severe asthma," Inflammation and Allergy Drug Targets, 2012.

[23] S. Siddiqui, N. S. Redhu, O. O. Ojo et al., "Emerging airway smooth muscle targets to treat asthma," Pulmonary Pharmacology \& Therapeutics, vol. 5539, no. 12, pp. 1094-10., 2012.

[24] M. Meissner, E. M. Valesky, S. Kippenberger, and R. Kaufmann, "Dimethyl fumarate-only an anti-psoriatic medication?" Journal der Deutschen Dermatologischen Gesellschaft, vol. 10, no. 11, pp. 793-801, 2012.

[25] Y. A. Alrashdan, H. Alkhouri, E. Chen et al., "Asthmatic airway smooth muscle CXCL10 production: mitogen-activated protein kinase JNK involvement," American Journal of Physiology, vol. 302, no. 10, pp. L1118-L1127, 2012.

[26] P. Seidel, I. Merfort, J. M. Hughes, B. G. G. Oliver, M. Tamm, and M. Roth, "Dimethylfumarate inhibits NF- $\kappa$ B function at multiple levels to limit airway smooth muscle cell cytokine secretion," American Journal of Physiology, vol. 297, no. 2, pp. L326-L339, 2009.

[27] P. Seidel, K. Hostettler, J. Hughes, M. Tamm, and M. Roth, "Dimethylfumarate inhibits CXCL10 via heme-oxygenase-1 in airway smooth muscle," European Respiratory Journal, vol. 41, no. 1, pp. 195-202, 2013.

[28] P. Seidel, I. Merfort, M. Tamm, and M. Roth, "Inhibition of $\mathrm{NF}-\kappa \mathrm{B}$ and AP-1 by dimethylfumarate correlates with downregulated IL-6 secretion and proliferation in human lung fibroblasts," Swiss Medical Weekly, vol. 140, p. w13132, 2010.

[29] L. Woodman, S. Siddiqui, G. Cruse et al., "Mast cells promote airway smooth muscle cell differentiation via autocrine upregulation of TGF- $\beta 1$," Journal of Immunology, vol. 181, no. 7, pp. 5001-5007, 2008.

[30] P. Berger, D. W. Perng, H. Thabrew et al., “Tryptase and agonists of PAR-2 induce the proliferation of human airway smooth muscle cells," Journal of Applied Physiology, vol. 91, no. 3, pp. 1372-1379, 2001.

[31] P. Berger, P. O. Girodet, H. Begueret et al., “Tryptase-stimulated human airway smooth muscle cells induce cytokine synthesis and mast cell chemotaxis," The FASEB Journal, vol. 17, no. 14, pp. 2139-2141, 2003.

[32] A. L. Lazaar, S. M. Albelda, J. M. Pilewski, B. Brennan, E. Puré, and R. A. Panettieri, "T lymphocytes adhere to airway smooth muscle cells via integrins and CD44 and induce smooth muscle cell DNA synthesis," Journal of Experimental Medicine, vol. 180, no. 3, pp. 807-816, 1994.

[33] C. E. Brightling, A. J. Ammit, D. Kaur et al., "The CXCL10/CXCR3 axis mediates human lung mast cell migration to asthmatic airway smooth muscle," American Journal of 
Respiratory and Critical Care Medicine, vol. 171, no. 10, pp. 1103-1108, 2005.

[34] N. G. Carroll, S. Mutavdzic, and A. L. James, "Distribution and degranulation of airway mast cells in normal and asthmatic subjects," European Respiratory Journal, vol. 19, no. 5, pp. 879885, 2002.

[35] P. Seidel, M. Roth, Q. Ge, I. Merfort, C. T. S'ng, and A. J. Ammit, " $\mathrm{I} \kappa \mathrm{B} \alpha$ glutathionylation and reduced histone $\mathrm{H} 3$ phosphorylation inhibit eotaxin and RANTES," European Respiratory Journal, vol. 38, no. 6, pp. 1444-1452, 2011.

[36] P. Seidel, S. Goulet, K. Hostettler, M. Tamm, and M. Roth, "DMF inhibits PDGF-BB induced airway smooth muscle cell proliferation through induction of heme-oxygenase-1," Respiratory Research, vol. 11, article 145, 2010.

[37] D. Van Ly, N. J. King, L. M. Moir, J. K. Burgess, J. L. Black, and B. G. Oliver, "Effects of $\beta_{2}$ agonists, corticosteroids, and novel therapies on rhinovirus-induced cytokine release and rhinovirus replication in primary airway fibroblasts," Journal of Allergy, vol. 2011, Article ID 457169, 11 pages, 2011.

[38] D. J. Lalor, B. Truong, S. Henness et al., "Mechanisms of serum potentiation of GM-CSF production by human airway smooth muscle cells," American Journal of Physiology, vol. 287, no. 5, pp. L1007-L1016, 2004.

[39] D. L. Clarke, R. L. Clifford, S. Jindarat et al., "TNF $\alpha$ and IFN $\gamma$ synergistically enhance transcriptional activation of CXCL10 in human airway smooth muscle cells via STAT-1, NF- $\kappa$ B, and the transcriptional coactivator CREB-binding protein," Journal of Biological Chemistry, vol. 285, no. 38, pp. 29101-29110, 2010.

[40] E. L. Hardaker, A. M. Bacon, K. Carlson et al., "Regulation of TNF-alpha- and IFN-gamma-induced CXCL10 expression: participation of the airway smooth muscle in the pulmonary inflammatory response in chronic obstructive pulmonary disease," The FASEB Journal, vol. 18, no. 1, pp. 191-193, 2004.

[41] P. Seidel, H. Alkhouri, D. J. Lalor, J. K. Burgess, C. L. Armour, and J. M. Hughes, "Thiazolidinediones inhibit airway smooth muscle release of the chemokine CXCL10: in vitro comparison with current asthma therapies," Respiratory Research, vol. 13, p. 90, 2012.

[42] T. Trian, G. Benard, H. Begueret et al., "Bronchial smooth muscle remodeling involves calcium-dependent enhanced mitochondrial biogenesis in asthma," Journal of Experimental Medicine, vol. 204, no. 13, pp. 3173-3181, 2007.

[43] P. Borger, N. Miglino, M. Baraket, J. L. Black, M. Tamm, and M. Roth, "Impaired translation of CCAAT/enhancer binding protein $\alpha$ mRNA in bronchial smooth muscle cells of asthmatic patients," Journal of Allergy and Clinical Immunology, vol. 123, no. 3, pp. 639-645, 2009.

[44] J. M. Coleman, C. Naik, F. Holguin et al., "Epithelial eotaxin-2 and eotaxin-3 expression: relation to asthma severity, luminal eosinophilia and age at onset," Thorax, vol. 67, pp. 1061-1066, 2012.

[45] Y. J. Lee, K. W. Kim, B. S. Choi, M. H. Sohn, and K. E. Kim, "Clinical characteristics of eosinophilic and noneosinophilic asthma in children," Acta Paediatrica, vol. 102, no. 1, pp. 53-57, 2012.

[46] H. F. Rosenberg, K. D. Dyer, and P. S. Foster, "Eosinophils: changing perspectives in health and disease," Nature Reviews Immunology, vol. 13, no. 1, pp. 9-22, 2012.

[47] O. Ghaffar, Q. Hamid, P. M. Renzi et al., "Constitutive and cytokine-stimulated expression of eotaxin by human airway smooth muscle cells," American Journal of Respiratory and Critical Care Medicine, vol. 159, no. 6, pp. 1933-1942, 1999.
[48] C. Pepe, S. Foley, J. Shannon et al., "Differences in airway remodeling between subjects with severe and moderate asthma," Journal of Allergy and Clinical Immunology, vol. 116, no. 3, pp. 544-549, 2005.

[49] R. Saunders, A. Sutcliffe, L. Woodman et al., "The airway smooth muscle CCR3/CCL11 axis is inhibited by mast cells," Allergy, vol. 63, no. 9, pp. 1148-1155, 2008.

[50] P. J. Chang, P. K. Bhavsar, C. Michaeloudes, N. Khorasani, and K. F. Chung, "Corticosteroid insensitivity of chemokine expression in airway smooth muscle of patients with severe asthma," Journal of Allergy and Clinical Immunology, vol. 130, no. 4, pp. 877-885, 2012.

[51] M. Odaka, S. Matsukura, H. Kuga et al., "Differential regulation of chemokine expression by Th1 and Th2 cytokines and mechanisms of eotaxin/CCL-11 expression in human airway smooth muscle cells," International Archives of Allergy and Immunology, vol. 143, no. 1, pp. 84-88, 2007.

[52] V. Chan, J. K. Burgess, J. C. Ratoff et al., "Extracellular matrix regulates enhanced eotaxin expression in asthmatic airway smooth muscle cells," American Journal of Respiratory and Critical Care Medicine, vol. 174, no. 4, pp. 379-385, 2006.

[53] R. Halwani, J. Al-Abri, M. Beland et al., "CC and CXC chemokines induce airway smooth muscle proliferation and survival," Journal of Immunology, vol. 186, no. 7, pp. 4156-4163, 2011.

[54] T. J. Schall, K. Bacon, K. J. Toy, and D. V. Goeddel, "Selective attraction of monocytes and T lymphocytes of the memory phenotype by cytokine RANTES," Nature, vol. 347, no. 6294, pp. 669-671, 1990.

[55] L. Pang, M. Nie, L. Corbett, A. Sutcliffe, and A. J. Knox, "Mast cell $\beta$-tryptase selectively cleaves eotaxin and RANTES and abrogates their eosinophil chemotactic activities," Journal of Immunology, vol. 176, no. 6, pp. 3788-3795, 2006.

[56] N. Berkman, V. L. Krishnan, T. Gilbey et al., "Expression of RANTES mRNA and protein in airways of patients with mild asthma," American Journal of Respiratory and Critical Care Medicine, vol. 154, no. 6, pp. 1804-1811, 1996.

[57] U. Oltmanns, R. Issa, M. B. Sukkar, M. John, and K. F. Chung, "Role of c-jun N-terminal kinase in the induced release of GMCSF, RANTES and IL-8 from human airway smooth muscle cells," British Journal of Pharmacology, vol. 139, no. 6, pp. 12281234, 2003.

[58] A. J. Ammit, A. L. Lazaar, C. Irani et al., "Tumor necrosis factor$\alpha$-induced secretion of RANTES and interleukin- 6 from human airway smooth muscle cells: Modulation by glucocorticoids and $\beta$-agonists," American Journal of Respiratory Cell and Molecular Biology, vol. 26, no. 4, pp. 465-474, 2002.

[59] P. L. Kuo, Y. L. Hsu, M. S. Huang, S. L. Chiang, and Y. C. Ko, "Bronchial epithelium-derived IL-8 and RANTES increased bronchial smooth muscle cell migration and proliferation by Krüppel-like factor 5 in areca nut-mediated airway remodeling," Toxicological Sciences, vol. 121, no. 1, pp. 177-190, 2011.

[60] J. Chhabra, Y. Z. Li, H. Alkhouri et al., "Histamine and tryptase modulate asthmatic airway smooth muscle GM-CSF and RANTES release," European Respiratory Journal, vol. 29, no. 5, pp. 861-870, 2007.

[61] W. Schweckendiek, "Treatment of psoriasis vulgaris," Medizinische Monatsschrift, vol. 13, no. 2, pp. 103-104, 1959.

[62] C. Nieboer, D. de Hoop, A. C. Van Loenen, P. N. J. Langendijk, and E. Van Dijk, "Systemic therapy with fumaric acid derivatives: New possibilities in the treatment of psoriasis," Journal of 
the American Academy of Dermatology, vol. 20, no. 4, pp. 601608,1989 .

[63] M. J. Harries, R. J. G. Chalmers, and C. E. M. Griffiths, "Fumaric acid esters for severe psoriasis: a retrospective review of 58 cases," British Journal of Dermatology, vol. 153, no. 3, pp. 549$551,2005$.

[64] A. Nast, I. Kopp, M. Augustin et al., "German evidencebased guidelines for the treatment of Psoriasis vulgaris (short version)," Archives of Dermatological Research, vol. 299, no. 3, pp. 111-138, 2007.

[65] M. R. Yazdi and U. Mrowietz, "Fumaric acid esters," Clinics in Dermatology, vol. 26, no. 5, pp. 522-526, 2008.

[66] L. Kappos, R. Gold, D. H. Miller et al., "Efficacy and safety of oral fumarate in patients with relapsing-remitting multiple sclerosis: a multicentre, randomised, double-blind, placebo-controlled phase IIb study," The Lancet, vol. 372, no. 9648, pp. 1463-1472, 2008.

[67] R. J. Fox, D. H. Miller, J. T. Phillips et al., "Placebo-controlled phase 3 study of oral BG-12 or glatiramer in multiple sclerosis," The New England Journal of Medicine, vol. 367, no. 12, pp. 10871097, 2012.

[68] R. Gold, R. A. Linker, and M. Stangel, "Fumaric acid and its esters: An emerging treatment for multiple sclerosis with antioxidative mechanism of action," Clinical Immunology, 2011.

[69] U. Mrowietz, E. Christophers, and P. Altmeyer, "Treatment of severe psoriasis with fumaric acid esters: Scientific background and guidelines for therapeutic use," British Journal of Dermatology, vol. 141, no. 3, pp. 424-429, 1999.

[70] U. Mrowietz, E. Christophers, and P. Altmeyer, "Treatment of psoriasis with fumaric acid esters: Results of a prospective multicentre study," British Journal of Dermatology, vol. 138, no. 3, pp. 456-460, 1998.

[71] U. Mrowietz, P. Altmeyer, T. Bieber, M. Röcken, R. E. Schopf, and W. Sterry, "Treatment of psoriasis with fumaric acid esters (Fumaderm)," Journal of the German Society of Dermatology, vol. 5, no. 8, pp. 716-717, 2007.

[72] J. J. Hoefnagel, H. B. Thio, R. Willemze, and J. N. Bouwes Bavinck, "Long-term safety aspects of systemic therapy with fumaric acid esters in severe psoriasis," British Journal of Dermatology, vol. 149, no. 2, pp. 363-369, 2003.

[73] C. Nieboer, D. de Hoop, P. N. J. Langendijk, A. C. Van Loenen, and J. Gubbels, "Fumaric acid therapy in psoriasis: a doubleblind comparison between fumaric acid compound therapy and monotherapy with dimethylfumaric acid ester," Dermatologica, vol. 181, no. 1, pp. 33-37, 1990.

[74] N. H. Litjens, J. Burggraaf, E. van Strijen et al., "Pharmacokinetics of oral fumarates in healthy subjects," British Journal of Clinical Pharmacology, vol. 58, no. 4, pp. 429-432, 2004.

[75] M. Vandermeeren, S. Janssens, M. Borgers, and J. Geysen, "Dimethylfumarate is an inhibitor of cytokine-induced Eselectin, VCAM-1, and ICAM-1 expression in human endothelial cells," Biochemical and Biophysical Research Communications, vol. 234, no. 1, pp. 19-23, 1997.

[76] B. Gesser, C. Johansen, M. K. Rasmussen et al., "Dimethylfumarate specifically inhibits the mitogen and stress-activated kinases 1 and 2 (MSK1/2): possible role for its anti-psoriatic effect," Journal of Investigative Dermatology, vol. 127, no. 9, pp. 2129-2137, 2007.

[77] T. J. Schmidt, M. Ak, and U. Mrowietz, "Reactivity of dimethyl fumarate and methylhydrogen fumarate towards glutathione and N-acetyl-1-cysteine-Preparation of S-substituted thiosuccinic acid esters," Bioorganic and Medicinal Chemistry, vol. 15, no. 1, pp. 333-342, 2007.

[78] M. Rostami-Yazdi, B. Clement, T. J. Schmidt, D. Schinor, and U. Mrowietz, "Detection of metabolites of fumaric acid esters in human urine: implications for their mode of action," The Journal of Investigative Dermatology, vol. 129, no. 1, pp. 231-234, 2009.

[79] K. Reich, D. Thaci, U. Mrowietz, A. Kamps, M. Neureither, and T. Luger, "Efficacy and safety of fumaric acid esters in the longterm treatment of psoriasis-a retrospective study (FUTURE)," Journal of the German Society of Dermatology, vol. 7, no. 7, pp. 603-611, 2009.

[80] F. Treumer, K. Zhu, R. Gläser, and U. Mrowietz, "Dimethylfumarate is a potent inducer of apoptosis in human T cells," Journal of Investigative Dermatology, vol. 121, no. 6, pp. 13831388, 2003.

[81] S. Gerdes, K. Shakery, and U. Mrowietz, "Dimethylfumarate inhibits nuclear binding of nuclear factor $\kappa \mathrm{B}$ but not of nuclear factor of activated $\mathrm{T}$ cells and CCAAT/enhancer binding protein $\beta$ in activated human T cells," British Journal of Dermatology, vol. 156, no. 5, pp. 838-842, 2007.

[82] S. Höxtermann, C. Nüchel, and P. Altmeyer, "Fumaric acid esters suppress peripheral CD4- and CD8-positive lymphocytes in psoriasis," Dermatology, vol. 196, no. 2, pp. 223-230, 1998.

[83] H. J. Bovenschen, A. M. G. Langewouters, and P. C. M. Van De Kerkhof, "Dimethylfumarate for psoriasis: pronounced effects on lesional T-cell subsets, epidermal proliferation and differentiation, but not on natural killer T cells in immunohistochemical study," American Journal of Clinical Dermatology, vol. 11, no. 5, pp. 343-350, 2010.

[84] H. Peng, M. Guerau-de-Arellano, V. B. Mehta et al., "Dimethyl fumarate inhibits dendritic cell maturation via nuclear factor $\kappa \mathrm{B}(\mathrm{NF}-\kappa \mathrm{B})$ and extracellular signal-regulated kinase 1 and 2 (ERK1/2) and mitogen stress-activated kinase 1 (MSK1) signaling," The Journal of Biological Chemistry, vol. 287, no. 33, pp. 28017-28026, 2012.

[85] T. J. Stoof, J. Flier, S. Sampat, C. Nieboer, C. P. Tensen, and D. M. Boorsma, "The antipsoriatic drug dimethylfumarate strongly suppresses chemokine production in human keratinocytes and peripheral blood mononuclear cells," British Journal of Dermatology, vol. 144, no. 6, pp. 1114-1120, 2001.

[86] B. Gesser, M. K. Rasmussen, L. Raaby et al., "Dimethylfumarate inhibits MIF-induced proliferation of keratinocytes by inhibiting MSK1 and RSK1 activation and by inducing nuclear p-c-Jun (S63) and p-p53 (S15) expression," Inflammation Research, vol. 60, no. 7, pp. 643-553, 2011.

[87] J. C. U. Lehmann, J. J. Listopad, C. U. Rentzsch et al., "Dimethylfumarate induces immunosuppression via glutathione depletion and subsequent induction of heme oxygenase 1," Journal of Investigative Dermatology, vol. 127, no. 4, pp. 835-845, 2007.

[88] R. Loewe, W. Holnthoner, M. Gröger et al., "Dimethylfumarate inhibits TNF-induced nuclear entry of NF- $\kappa \mathrm{B} / \mathrm{p} 65$ in human endothelial cells," Journal of Immunology, vol. 168, no. 9, pp. 4781-4787, 2002.

[89] K. Wallbrecht, N. Drick, A. C. Hund, and M. P. Schon, "Downregulation of endothelial adhesion molecules by dimethylfumarate, but not monomethylfumarate, and impairment of dynamic lymphocyte-endothelial cell interactions," Experimental Dermatology, vol. 20, no. 12, pp. 980-985, 2011.

[90] M. Meissner, M. Doll, I. Hrgovic et al., "Suppression of VEGFR2 expression in human endothelial cells by dimethylfumarate 
treatment: evidence for anti-angiogenic action," Journal of Investigative Dermatology, vol. 131, no. 6, pp. 1356-1364, 2011.

[91] D. H. Lee, R. Gold, and R. A. Linker, "Mechanisms of oxidative damage in multiple sclerosis and neurodegenerative diseases: therapeutic modulation via fumaric acid esters," International Journal of Molecular Sciences, vol. 13, no. 9, pp. 11783-11781, 1803.

[92] S. Schimrigk, N. Brune, K. Hellwig et al., "Oral fumaric acid esters for the treatment of active multiple sclerosis: an openlabel, baseline-controlled pilot study," European Journal of Neurology, vol. 13, no. 6, pp. 604-610, 2006.

[93] R. Gold, L. Kappos, D. L. Arnold et al., "DEFINE Study Investigators. Placebo-controlled phase 3 study of oral BG-12 for relapsing multiple sclerosis," The New England Journal of Medicine, vol. 367, no. 12, pp. 1098-1107, 2012.

[94] P. Albrecht, I. Bouchachia, N. Goebels et al., "Effects of dimethyl fumarate on neuroprotection and immunomodulation," Journal of Neuroinflammation, vol. 9, p. 163, 2012.

[95] S. X. Lin, L. Lisi, C. Dello Russo et al., “The anti-inflammatory effects of dimethyl fumarate in astrocytes involve glutathione and haem oxygenase-1," ASN Neuro, vol. 3, no. 2, pp. 75-84, 2011.

[96] R. H. Scannevin, S. Chollate, M. Y. Jung et al., "Fumarates promote cytoprotection of central nervous system cells against oxidative stress via the nuclear factor (erythroid-derived 2)like 2 pathway," Journal of Pharmacology and Experimental Therapeutics, vol. 341, no. 1, pp. 274-284, 2012.

[97] L. A. Hart, V. L. Krishnan, I. M. Adcock, P. J. Barnes, and K. F. Chung, "Activation and localization of transcription factor, nuclear factor- $\kappa \mathrm{B}$, in asthma," American Journal of Respiratory and Critical Care Medicine, vol. 158, no. 5, pp. 1585-1592, 1998.

[98] M. C. Catley, M. B. Sukkar, K. F. Chung et al., "Validation of the anti-inflammatory properties of small-molecule $\mathrm{I} \kappa \mathrm{B}$ kinase (IKK)-2 inhibitors by comparison with adenoviralmediated delivery of dominant-negative IKK1 and IKK2 in human airways smooth muscle," Molecular Pharmacology, vol. 70, no. 2, pp. 697-705, 2006.

[99] W. R. Henderson, E. Y. Chi, J. L. Teo, C. Nguyen, and M. Kahn, "A small molecule inhibitor of redox-regulated NF- $\kappa$ B and activator protein-1 transcription blocks allergic airway inflammation in a mouse asthma model," Journal of Immunology, vol. 169, no. 9, pp. 5294-5299, 2002.

[100] V. Tergaonkar, "NFאB pathway: a good signaling paradigm and therapeutic target," International Journal of Biochemistry and Cell Biology, vol. 38, no. 10, pp. 1647-1653, 2006.

[101] B. C. Liao, C. W. Hsieh, Y. C. Lin, and B. S. Wung, "The glutaredoxin/glutathione system modulates NF- $\kappa$ B activity by glutathionylation of p65 in cinnamaldehyde-treated endothelial cells," Toxicological Sciences, vol. 116, no. 1, pp. 151-163, 2010.

[102] I. S. Kil, S. Y. Kim, and J. W. Park, "Glutathionylation regulates $\mathrm{I} \kappa \mathrm{B}$," Biochemical and Biophysical Research Communications, vol. 373, no. 1, pp. 169-173, 2008.

[103] S. A. Cross, D. R. Cook, A. W. Chi et al., "Dimethyl fumarate, an immune modulator and inducer of the antioxidant response, suppresses HIV replication and macrophage-mediated neurotoxicity: a novel candidate for HIV neuroprotection," The Journal of Immunology, vol. 187, no. 10, pp. 5015-5025, 2011.

[104] P. Kirkham and I. Rahman, "Oxidative stress in asthma and COPD: antioxidants as a therapeutic strategy," Pharmacology and Therapeutics, vol. 111, no. 2, pp. 476-494, 2006.

[105] W. A. Wuyts, B. M. Vanaudenaerde, L. J. Dupont, M. G. Demedts, and G. M. Verleden, "N-acetylcysteine reduces chemokine release via inhibition of p38 MAPK in human airway smooth muscle cells," European Respiratory Journal, vol. 22, no. 1, pp. 43-49, 2003.

[106] S. S. Brar, T. P. Kennedy, A. B. Sturrock et al., "NADPH oxidase promotes NF- $\kappa$ B activation and proliferation in human airway smooth muscle," American Journal of Physiology, vol. 282, no. 4, pp. L782-L795, 2002.

[107] D. Morse and A. M. K. Choi, "Heme oxygenase-1: from bench to bedside," American Journal of Respiratory and Critical Care Medicine, vol. 172, no. 6, pp. 660-670, 2005.

[108] A. Almolki, C. Taillé, G. F. Martin et al., "Heme oxygenase attenuates allergen-induced airway inflammation and hyperreactivity in guinea pigs," American Journal of Physiology, vol. 287, no. 1, pp. L26-L34, 2004.

[109] L. E. Otterbein, J. K. Kolls, L. L. Mantell, J. L. Cook, J. Alam, and A. M. Choi, "Exogenous administration of heme oxygenase-1 by gene transfer provides protection against hyperoxia-induced lung injury," The Journal of Clinical Investigation, vol. 103, no. 7, pp. 1047-1054, 1999.

[110] C. Michaeloudes, P. J. Chang, M. Petrou, and K. F. Chung, "Transforming growth factor- $\beta$ and nuclear factor E2-related factor 2 regulate antioxidant responses in airway smooth muscle cells: role in asthma," American Journal of Respiratory and Critical Care Medicine, vol. 184, no. 8, pp. 894-903, 2011. 


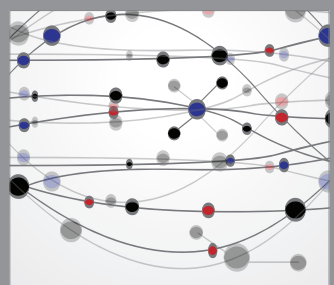

The Scientific World Journal
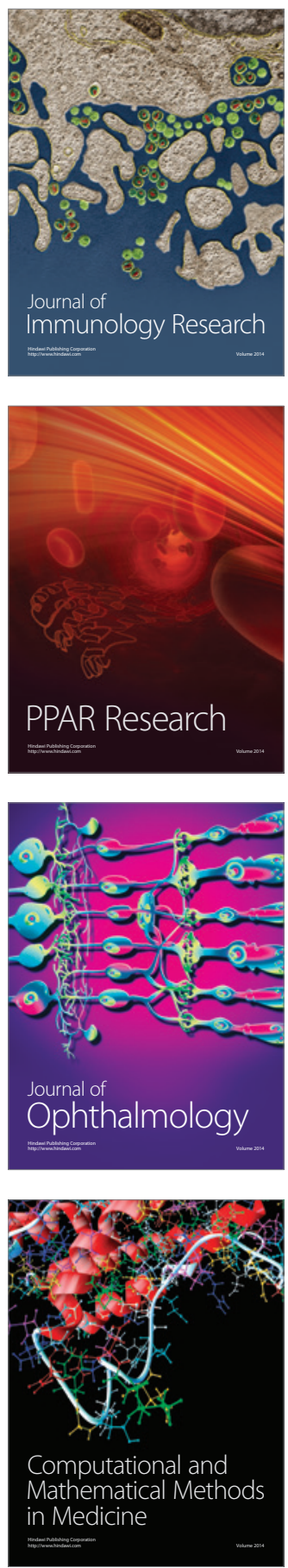

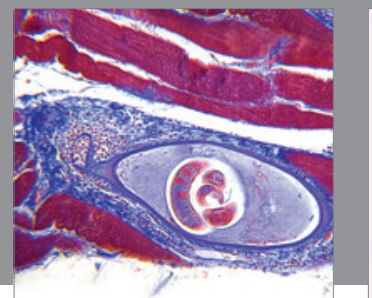

Gastroenterology

Research and Practice
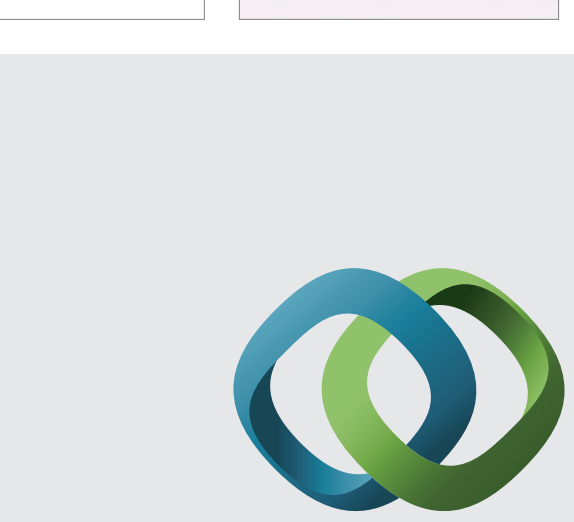

\section{Hindawi}

Submit your manuscripts at

http://www.hindawi.com
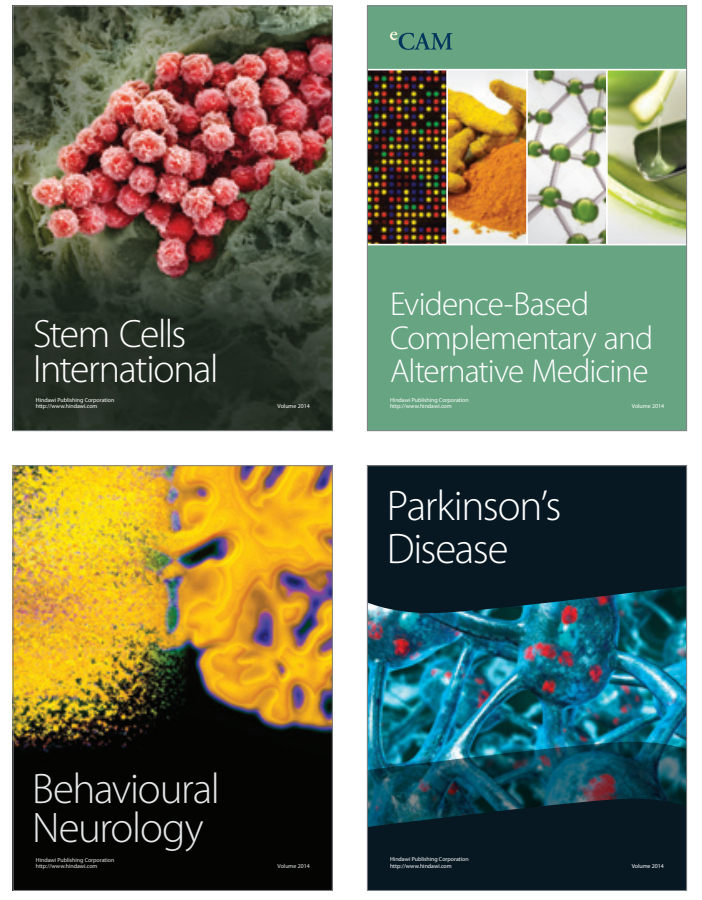
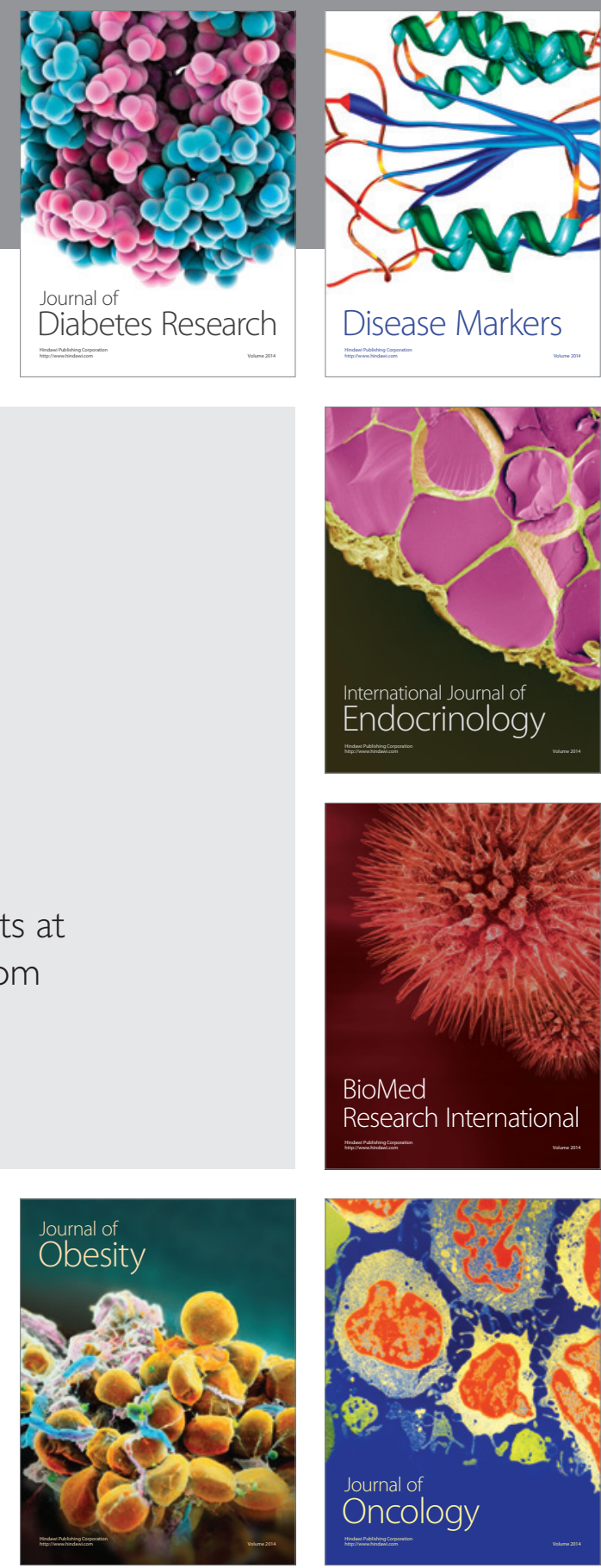

Disease Markers
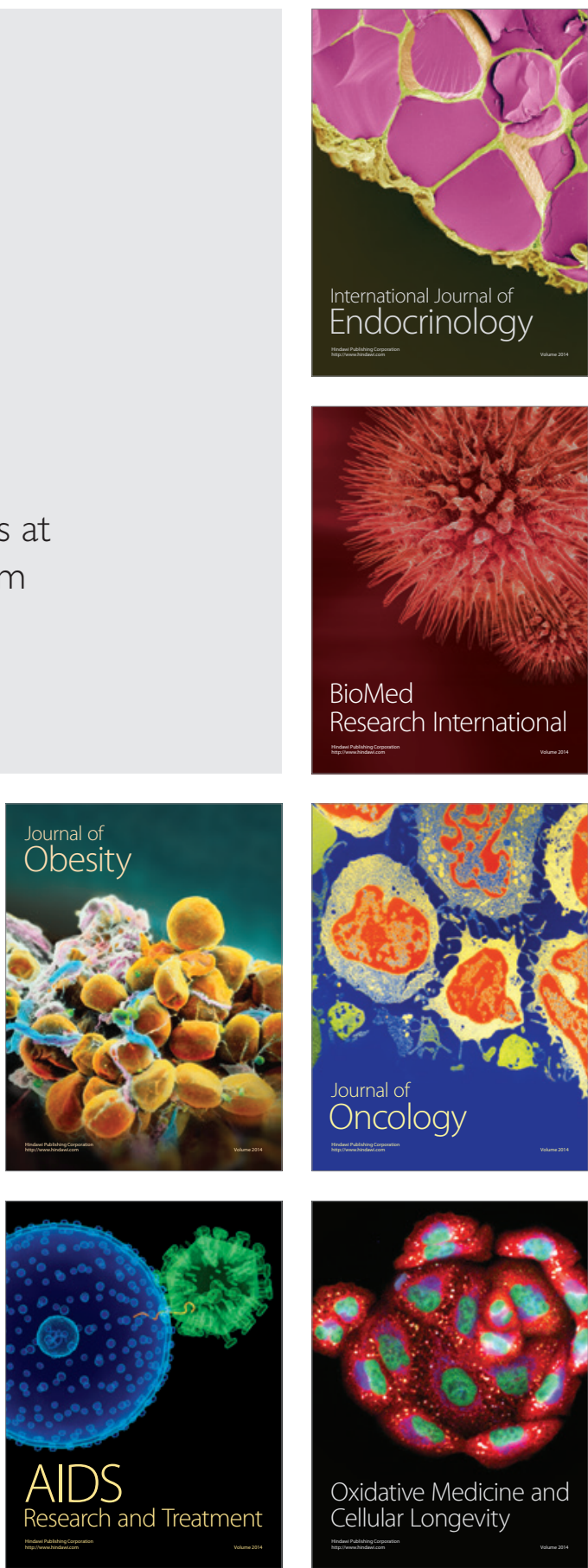